\title{
Sources of Meaning in the Acquisition of Complex Syntax: The Sample Case of Causality ${ }^{1}$
}

Lois Bloom and Joanne Bitetti Capatides

CitATion: Bloom, L., Capatides, J. (1987). Sources of meaning in complex syntax: The sample case of causality. Journal of Experimental Child Psychology, 43, 112-128; Reprinted in Bloom, L. (1991). Language development from two to three, New York: Cambridge University, pp. 377-393.

\begin{abstract}
The study reported here is concerned with how children acquire complex sentences for expressing their beliefs about causally related events, in the transition in language development from simple to complex syntax. Subjects were three girls and four boys, observed longitudinally in their homes from 26 to about 38 months of age. Data analysis began with those observations in which each child began to produce causally related propositions without syntactic connectives, and continued until the children were about 3 years old. Two broad categories of causal meaning were expressed in the children's causal statements. Objective meaning concerned means-end and consequence relations that were evidential and fixed in the physical world. Subjective meaning expressed causal connections concerned with personal, affective, or sociocultural beliefs. While most of the children's statements expressed subjective meaning overall, the acquisition of syntactic connectives was associated with objective meaning. These results are discussed in terms of (a) the development of these children's understanding of causality and (b) the acquisition of increasingly complex language.
\end{abstract}

The transition in language development from a simple sentence grammar to complex syntax begins between 2 and 3 years of age. As a sample case of this transition to complex sentences that express increasingly complex ideas, we have inquired into how young children acquire the language for expressing their beliefs about causally related events in the world. This study concerns the meanings of children's early causal language: When children begin to combine propositions with a causal connection between them, what kinds of meaning do they express? This question is relevant not only to children's language development but also to the inferences we can draw from their causal language about their underlying concept of causality. How do the meanings of children's early causal statements relate to what we know, first, from psychological accounts of the development of causal understanding and, second, from philosophical theories of causality in the world?

\section{Theories of Causality and the Development of Causality}

Three models of causality are relevant to attempts to understand the development of causal understanding: the empiricist model of Hume (1739/1889); the rationalist theory of innate ideas attributed to Kant (1781/1965); and contemporary theories of intentionality, for example, Hart and Honoré (1959) and Searle (1983). According to Hume, inferring a causal connection between events in the world depends on detecting certain observable regularities in the physical world: When two events occur together, one after the other, and consistently in relation to each other, then one can infer that the relation between them is a causal one. In Hume's model, the development of causality depends upon the child's detecting these empirical regularities of contiguity, order, and

\footnotetext{
${ }^{1}$ The research reported here was supported by Fellowship F1-MH-30,001, 1965-1968, from the National Institute of Mental Health; Research Grant HD 03828, 1971-1974, from the National Institute of Child Health and Development; and Research Grants from the National Science Foundation, 1975-1987, to Lois Bloom. The study was published originally in the Journal of Experimental Child Psychology, 43, 112-128; reprinted in Bloom, L. (1991). Language development from two to three, New York: Cambridge University, pp. 377-393; and reformatted for this digital version with slight changes in organization and minor text editing.
} 
constant conjunction in physical and mechanical events. The principles of causal reasoning, then, depend on the structure of events in the world, and the child's task is to detect their regularities.

For Kant, in contrast, causality is an innate property of the mind according to which causal connections are attributed to physical events. The individual's concept of causality determines the structure of reality, conferring the causal connections on events in the world for the regularities that we observe. In this model, the development of causality depends upon an underlying conceptual mechanism for causal understanding. Psychological investigations into the development of causality have proceeded on the basis of one or another of these two philosophical points of view (see, for example, Bullock, Gelman, \& Baillargeon, 1982; Sedlak \& Kurtz, 1981; Shultz, 1982).

Intentional theories of causality, in contrast, emphasize that actions and perceptions of persons establish causal connections, rather than physical and mechanical regularities in the world or a predetermined mental concept. That is, we discover causality by experiencing it through our actions and perceptions (Searle, 1983). A cause is essentially something that intervenes to change the normal course of events, and the intervention is often a human one (Ducasse, 1924/1969). And in matters of jurisprudence, the two central concepts of causation in the law depend upon (1) a person's manipulating things in order to bring about an intended change, or (2) one person, by word or deed, providing another with a reason for acting (Hart \& Honoré, 1959). In this view, the concept of causality develops as children learn to regulate their actions and interactions in the world.

Piaget's developmental account of the foundations of causality in infancy, before language, is consistent with theories that implicate human perceptions and actions in causal attributions. For Piaget (1937/1954) the adult operates with a concept of causality but this property of the mind is not innately determined. Rather, causality is constructed by the child, over time, on the basis of (1) the child's own actions and the actions of others that bring about change, and (2) the child's observations of the regularities and correlations in the world associated with such change.

The essence of sensorimotor causality in infancy is a relation between actions and their physical effects and involves sequences or chains of events that can be perceived directly, for example, pulling a string and watching the toy move. Action and effect gradually became dissociated as the infant comes to perceive other intermediary objects, notably persons, that touch one another in the context of such change. Soon the infant uses an adult as an intermediary-grasping the adult's hand and steering it or directing it to perform an action. Development of the concept of causality, then, begins in infancy with the child's own actions that bring about change, and the child's getting other persons to bring about change (Piaget, 1937/1954, 1971/1974).

Causality is at first limited to the data of perception, to what is evident in the context. Gradually, the child becomes able to reconstruct a cause in the presence of an effect, and inversely, given an object, the child can foresee its future effects. A mental construction-involving new situations and not merely familiar relationships-supersedes direct contact and action. Such mental representations of events that are not given in the context are, however, mental representations of objective causal connections with perceptible content.

Another source of the development of causal understanding that is not often considered is the information about causal connections in the discourse that the child hears. Language input can lead the child to discover the bases for causal attribution in physical events, for instance, when someone tells the child not to throw a glass "because it will break." And the language that the child hears in interactions is a primary source for learning about causal connections in nonphysical events, for instance, "She is lonely because everyone went away." Once the child begins to participate in conversational discourse, linguistic input can provide the causal connections between antecedent and consequent events that cannot be experienced directly through action. For example, children as young as 3 years of age can complete a narrative sequence about events that are the causes or consequences of emotional states (Trabasso, Stein, \& Johnson, 1981).

As will be seen, the children in the present study began to express causal connections in complex sentences with two sources for the meanings of their causal statements. One source was their sensorimotor understanding of objective causal relations, and the other was subjective causal attributions provided in discourse with other persons. 
This study of the acquisition of the syntax of causal statements was concerned with the following questions: (1) What meanings are expressed in the causal statements of 2-year-old children, and (2) how do these meanings interact with the acquisition of the syntax of complex sentences? Thus, this study was concerned with form, the emergence of conjoined clauses, first without and then with syntactic connectives, in relation to meaning, the content of the semantic connection between the clauses and its relation to the underlying concept of causality.

\section{SUBJECTS AND PROCEDURES}

Seven children, three girls and four boys, were visited in their homes during their daily activities and informal play, from about two to three years of age, for the larger longitudinal study of early language acquisition of which this study of their expressions of causality is a part (reported in the papers collected in Bloom, 1991). Three of the children-Eric, Gia, and Kathryn-were visited for approximately eight hours over several days, every six weeks, and four children-David, Mariana, Paul, and Peter-were seen for approximately five hours every three weeks. The same or similar toys were brought to all the sessions, for the different children and for each child, in an effort to establish consistency in the home contexts among the children and over time. The observations were audio recorded, and the transcriptions included all speech by child and adult along with descriptions of nonlinguistic context and behavior. ${ }^{2}$

The study reported here followed the investigation of the forms and functions of these children's causal language reported by Hood and Bloom (1979). The data for the present study consisted of all the children's causal utterances except why questions from that earlier study, beginning with the observations in which each child began to produce causally related propositions without syntactic connectives, at about age two, and continuing until they were about 3 years old.

Although the analyses were done for each child individually, the children were similar in their profiles of development, so that the data could be pooled for reporting the results. The index that was used to pool the data was the rate of increase over time in the number of causal statements with connectives. As is well known, children differ from one another in onset and rate of development. The children in the present study began to say causal sentences with connectives at different ages (ranging from 26 months, 3 weeks to 31 months, 2 weeks), and they also differed in both the number of causal utterances in their speech and their average utterance length. For these reasons, the data could not be pooled according to age, mean length of utterance, or absolute frequency of causal utterance types or tokens. Accordingly, the individual transcriptions were assigned to developmental periods according to each child's individual rate of increasing frequency of causal statements with connectives. In this way, the children were each compared with themselves, and each served as her or his own control, so that differences between them in rate of development were controlled for.

The first developmental period, Period A, included the texts from all the children before syntactic connectives were productive in their causal statements (with productivity defined as five different causal utterances with connectives). To pool the data according to rate of development thereafter, each child's transcriptions were inspected for at least a twofold increase in the number of causal utterances with connectives from one observation to the next. Where a twofold increase (or greater) was found from one transcription to the next, the two transcriptions were considered to represent different developmental periods. When less than a two-fold increase occurred, the two transcriptions were included in the same developmental period. Based upon the rate of increase in the frequency of causal statements with connectives, three developmental periods (B, C, and D) were clearly discernible after Period A with no connectives. The number of observation sessions, total number of causal

${ }^{2}$ The procedures for data collection and transcription are described in greater detail in Bloom (1970, pp. 234-9). See, also, Bloom, Lightbown, and Hood (1975) and conventions for transcription of child language recordings, App. A, in Bloom \& Lahey (1978). The speech samples from Eric, Gia, and Kathryn were collected and transcribed by Lois Bloom. The speech samples from Peter were collected and transcribed by Lois Hood and Patsy Lightbown, who took turns interacting with Peter and taking notes on the situational context and behavior. David, Mariana, and Paul were visited by Lois Hood. The transcriptions of the Eric, Gia, Kathryn, and Peter data are stored for access by other researchers in the Special Collections at the Gottesman Memorial Libraries, Teachers College, Columbia University; transcripts of the Peter data are also part of the CHILDEs database, the Child Language Data Exchange System, Carnegie-Mellon University. 
utterances (except why questions), age range, and range of mean length of utterance for the four developmental periods are presented in Table 1.

Table 1. Description of Four Developmental Periods

\begin{tabular}{|c|c|c|c|c|c|c|c|}
\hline \multirow[b]{2}{*}{ Period } & \multirow{2}{*}{$\begin{array}{c}\text { Total } \\
\text { Utterances }\end{array}$} & \multirow[b]{2}{*}{ Sessions } & \multirow[b]{2}{*}{ Hours } & \multicolumn{2}{|l|}{ Age } & \multicolumn{2}{|c|}{$\begin{array}{l}\text { MLU } \\
\text { (Morphemes) }\end{array}$} \\
\hline & & & & Mean & Range & Mean & Range \\
\hline A & 194 & 13 & 76.5 & 26,3 & $24,2-30$ & 2.80 & $2.0-3.4$ \\
\hline B & 228 & 7 & $45 \cdot 5$ & 29,2 & $26,3-32$ & 3.42 & $2.8-4.2$ \\
\hline $\mathrm{C}$ & 495 & 11 & 68.5 & 31,3 & $29,2-35$ & 3.89 & $3.2-5.0$ \\
\hline D & 737 & 8 & 48.5 & 35,1 & $32,3-38$ & 4.11 & $3.1-5.0$ \\
\hline
\end{tabular}

$N=7$.

\section{Text Analyses}

The words utterance and statement are used throughout this paper as follows: An utterance refers to a speech unit, something the child said that is defined by both the discourse frame, that is, its occurrence relative to other utterances, and the limits of its topic. A causal statement is any utterance or succession of utterances that expressed a causal relation between propositions and did not have the form or function of a why question.

Both formal and semantic criteria were used to decide which utterances to include in the analyses. Formal criteria were (1) a causal word (e.g., because, so, if) in child utterances, and/or (2) a child utterance following an adult why question. Semantic criteria were based on the proposition as the unit of identification (see Ochs, Schieffelin, \& Platt, 1979, for discussion of this criterion). Utterances were included with propositional reference to two events or states with a causal relation between them, whether both propositions were spoken by the child (for example, "I can't eat these because the belly's full") or one proposition was spoken by the child and the other spoken by an adult, for example:

Adult: I have to pack up my toys now.

Child: because you're going home?

Thus, causal statements could extend across utterance boundaries and speaker turns. The unit of analysis was a causal relation between propositions, to distinguish children's causal statements from causal questions (with why), and lexical causatives (the use of such verbs as make in single proposition statements). The research reported here on complex sentences differs, then, from studies of the acquisition of causative verbs in singleproposition statements (Bowerman, 1974), and periphrastic causative structures (Baron, 1977; Shibatani, 1976).

Every causal statement was coded for form and meaning. The dimension of form was straightforward, whether the causal statement included a syntactic connective, that is, and, so, because, and if, and was coded directly from the linguistic texts. The dimension of meaning was inferential and depended upon an interpretation of what the child said in relation to topic and context. Causal meaning was inferred from the connection between some end state and the change in the context or the conditions that brought about the end state. The interpretive analysis followed the kinds of discovery procedures we have used in our earlier research (e.g., Bloom, 1970; Bloom, Lightbown, \& Hood, 1975; see also Bloom, Capatides, \& Tackeff, 1981; and Golinkoff, 1981, for discussion of the theoretical rationale for interpretive analysis). Because one does not know in advance which aspects of the child's behaviors will be most relevant to the developmental questions, discovery and resolution go hand in hand. Categories emerge, to begin with, as a result of identifying similarities and differences among speech events, and the categories are revised in the process of "fitting" more and more of the speech events to them, until as many of the events as possible are accounted for (the standard method followed in much of the research in ethology, cultural anthropology, and linguistics, e.g., Beer, 1973; Bloom, 1974; M. Harris, 1964; Vendler, 1962). 


\section{Reliability}

Only statements in which the causal meaning relation between propositions was interpretable and unambiguous, as agreed upon by two judges after each interpreted the utterances independently, were included in the analyses reported here. Utterances that were uninterpretable or ambiguous were those that could not be coded for semantic meaning because of insufficient contextual information. For the most part, they were not bizarre, nor were they "animistic" or otherwise similar to the precausality described by Piaget (1923/1955). For example, Eric said "made a bridge under so the man will watch," while he set up a "bridge" with a book; this utterance was not included because the context was insufficient for interpreting what he meant. The relative frequency of uninterpretable or otherwise ambiguous statements (with and without connectives) remained constant over time: $13 \%$, Period A; 13\%, Period B; 12\%, Period C; and 16\%, Period D.

The interpretive analysis was done by two investigators working together until the relevant dimensions of meaning were identified and categories of meaning were agreed upon. Subsequently, one of the original investigators recoded all the causal statements according to the meaning categories. A test of reliability was performed by having a third judge code a randomly selected text (consisting of 45 utterances) from one of the children (Mariana). The percentage of agreement between the original coding and the reliability coding was .84. Almost all the disagreements proved to be reconcilable scoring errors rather than judgment differences.

\section{RESULTS}

The results consist of description of the children's causal statements in terms of form (the use of connectives), meaning (categories of causal relations between propositions), and the covariation of form and meaning.

\section{Form}

The analysis of form was simply an analysis of whether or not the children used a syntactic connective to join two propositions in a causally related sequence, and was relatively straightforward. The children made causal statements without connectives (Period A) before they did so with connectives (beginning in Period B). The relative frequency of statements with connectives increased from $37 \%$ of all causal statements in Period B, to $71 \%$ in Period C, to 83\% in Period D.

\section{Meaning}

Two broad categories of causal meaning emerged from the interpretive analysis: objective and subjective meaning. Of the total number of utterances in Table 1, 86.5\% were interpretable. Subjective and objective meaning accounted for $94 \%$ of the interpretable causal utterances.

Objective meaning was evident and fixed in the physical world; the children were talking about events in which the causal relation was transparent and involved a minimum of inference. Statements with objective meaning expressed relations in which the first event or state of affairs and the resulting end state were perceptible, or imaginable if one or both were not part of the immediate context of the speech event. For example:

(1) M (Mariana picking up a pull toy

before it rolls over microphone wire) I'm gonna pick this up so it can't step on the cord.

(2) G

I don't have a Christmas tree.

Adult: Why?

Because throw it out.

Statements with objective meaning expressed a means-end relation, as in (1), a consequence relation (as in 2), or a condition, as in the following example:

(3) D (Tiny blue barrel is inside other barrels) You can't see it cause it's way inside.

Subjective meaning expressed causal relations that were not fixed relations or self-evident. Rather, they were causal connections that were presumably made by the child on the basis of a personal, affective, or sociocultural belief that was either the original state of affairs or the resulting end state. Whereas the causal connection in 
objective statements was a cause-effect relation that derived from a fixed physical order of events, the causal connection in subjective statements was derived from a constructed social order. For example:

(4) K (Lois starting to pack up her toys and leave) I'll help you too if you have a little trouble.

(5) G (playing with doll)

What shall we give him? Nothing.

Why? Because not hungry.

(6) M (Mariana reading picture book;

picture with train at red stop light) This one can't go.

Adult: It can't go?

No, because that sign doesn't say go.

(7) P (Peter has just shown adult his guinea pig)

Why do you have him? Did you

take him home from school?

Yeah, cause they don't belong in school.

(8) G I want to go home now.

Wait my mommy comes.

Why?

Because I will be lonely.

Both objective and subjective meaning had to do with events that involved human intervention, either personal or interpersonal. However, the two kinds of meanings were different according to how the child's statement matched the way events and states are typically associated in the world. Objective meaning had to do with a physical order in the world that is associated with actions and perceptions. Subjective meaning had to do with a cultural order that is agreed upon socially. This difference in relational meaning is illustrated in the following pairs of examples. In each pair (9) and (10), similar content was expressed, but a different causal relation was inferred. In Examples 9(a) and 10(a), the meaning relation is objective-one thing follows another because of the way they go together in the physical world. But in $9(\mathrm{~b})$ and $10(\mathrm{~b})$ the meaning relation is subjective-one thing follows another because of social or cultural custom:

(9a) P

You can't?

(9b) P (Peter, in another context)

(10a) G

(10b) K
I can't close that one.

No/because it's broken.

This was broken and I gotta fix it.

I gonna step in puddle with sandals on and get it all wet.

We didn't go anywhere/just stay home because it was all wet.

The children's causal statements, taken together with and without connectives, most often expressed subjective meanings. Throughout the four periods an average of $62 \%$ of their causal statements were subjective: $66 \%$ in Period A, 63\% in Period B, 57\% in Period C, and 63\% in Period D.

In sum, in the period from 2 to 3 years of age, when these children were learning to express causal relations between propositions in complex sentences, (1) they acquired the syntactic connectives and the frequency of connectives increased, and (2) they expressed both objective and subjective meanings, with subjective meaning expressed more often overall. Only form, the use of connectives, increased developmentally.

\section{Meaning and Connectives}

Although no developmental trend was apparent for meaning taken alone, the emergence of connectives and meaning interacted developmentally. On the basis of the relative frequency of statements with subjective meaning overall, causal statements could be expected to occur primarily with subjective meaning, regardless of whether a connective was expressed. If no fluctuations in this expected pattern of covariation of connectives and meaning occurred over time, then we could conclude that development is only quantitative and linguistic, with 
the only development being an increase in frequency of connectives. In contrast, fluctuations in the pattern of covariation of connectives with subjective and objective meaning could be interpreted as qualitative change in the developmental interaction between linguistic form and underlying conceptualization.

Subjective meaning was always more frequent in sentences without connectives for all the children, with only one exception (in the case of one child, four of his six sentences expressed objective meaning in Period A).

Table 2. Frequency of Causal Statements with Objective and Subjective Meaning, with and without Causal Connectives

\begin{tabular}{llll}
\hline Time & $\begin{array}{l}\text { No } \\
\text { Connective }\end{array}$ & Connective & Total \\
\hline Period B & & & \\
Objective & 34 & 45 & 79 \\
Subjective & 99 & 33 & 132 \\
Total & 133 & 78 & 211 \\
Period C & & & \\
Objective & 37 & 118 & 155 \\
Subjective & 67 & 138 & 205 \\
Total & 104 & 256 & 360 \\
Period D & & & \\
Objective & 23 & 197 & 220 \\
Subjective & 78 & 302 & 380 \\
Total & 101 & 499 & 600 \\
\hline$N=7$ & & &
\end{tabular}

However, in Period B, when connectives first emerged, subjective meaning was less frequent in sentences with connectives than in sentences without connectives, and more than half the causal statements with connectives expressed objective meaning (Table 2).

All the children showed the same developmental pattern over time in their acquisition of connectives with subjective or objective meaning. The influences of time and meaning on the acquisition of connectives were tested statistically using the logit form of log linear analysis (Knoke \& Burke, 1980), with the occurrence of connectives as the dependent variable. The data in Table 2 are categorical frequency data for the dependent variable of the connective (plus or minus connective in causal statements), in relation to time (Periods B, C, D) and meaning (objective, subjective) as the independent variables. The logit models for these data, presented in Table 3, test three hypotheses: that the use of connectives was related to developmental period; that the use of connectives was related to meaning, and (3) that the contingency between the use of connectives and meaning changed over time.

The use of connectives increased significantly over time, difference likelihood ratio $\left.\Delta L^{2}(2)=152.66, p<.01\right)$. The ratio of sentences with and without connectives increased from less than 1 to 1 in Period B to approximately 5 to 1 in Period D. The use of connectives was also significantly related to meaning, difference likelihood ratio $\Delta L^{2}(1)$ $=24.75, p<01$. In sentences without connectives overall, subjective meaning was far more frequent than objective meaning with a ratio of 2.6 to 1 . In sentences with connectives, the disparity was not as great, with a ratio of 1.3 to 1. 
Table 3. Logit Analysis for Frequencies of Causal Statements in Table 2

\begin{tabular}{lll}
\hline Effect & $\begin{array}{l}\text { Difference } \\
\text { Likelihood Ratio }\end{array}$ & $d f$ \\
\hline Time x connective & $152.66^{\mathrm{a}}$ & 2 \\
Meaning x connective & $24.75^{\mathrm{a}}$ & 1 \\
Time x meaning x connective & $5.96^{b}$ & 2 \\
\hline${ }^{a} p<.01$. & & \\
${ }^{b} p=05$. & & \\
$N=7$ & &
\end{tabular}

The relation between meaning and connective changed significantly over time, difference likelihood ratio $\Delta \mathrm{L}^{2}(2)$ $=5.96, p=.05$. In sentences without connectives, the ratio of subjective meaning to objective meaning varied from 3 to 1 in Period B, to about 2 to 1 in Period C, and to more than 3 to 1 in Period D. However, in sentences with connectives the ratio varied from less than 1 to 1 in Period B, to about 1 to $1 \mathrm{in} C$, and to 1.5 to 1 in Period D. In sum, subjective meaning predominated for statements with and without connectives combined; however, the acquisition of syntactic connectives in Period B was associated with expression of objective meaning. By Period $\mathrm{D}$, sentences both with and without connectives expressed subjective meaning primarily.

\section{DISCUSSION}

We discuss these results in terms of (1) the relation between these children's concept of causality and theories of causality and (2) the acquisition of increasingly complex language.

Two-Year-Old Causality

The picture of 2-year-old causality that emerged from the results of this study begins to bridge the gap between accounts of early sensorimotor causality and later physical and logical causality. Objective causal meanings in the children's statements represented a continuity in language of the kind of sensorimotor causality displayed earlier on the plane of action, having to do with evidential and action-based means-end and consequence relations. But even though they talked about causal relations that were evident between things in the physical order of the world, these perceptible causal events were not the kinds of physical and mechanical causality between objects that depend on the detection of empirical regularities. Rather, the concept of causality for the two year old children in this study, as reflected in the objective meanings of their causal statements, involved the causes and consequences of their actions in everyday events.

The children talked more often about subjective causal relations, with appeals to affective emotions and drives, personal judgments, and cultural practice that were a part of the social order of the world. One source of subjective meanings was in interactions with others in which the child could see either the affective consequences of an action (for example, seeing father angry when the child pokes the dog) or the behaviors of others in response to expression of emotions and feeling (for example, when the child cries and a caregiver comforts or feeds the child). But other causal connections were imperceptible and could have been learned only from the speech that the children heard (and overheard); for example, "this one can't go . . . because that sign (red stoplight) doesn't say go" and ("Did you take him home from school?") ... “yeah, 'cause they don't belong in school.” The children could not have discovered such relationships as these between events, and the feelings, personal judgments, or cultural beliefs that were causally associated with the events, by acting on the environment. Someone must have told them that red means stop and green means go, that guinea pigs do not belong in school, and so on. Much of what the children knew about subjective causality must have come when adults supplied them with beliefs, reasons, and justifications in past discourse.

Thus, the children learned about certain causal connections by acting and observing others act on the world and learned to express objective meanings that derived from the fixed physical order in such actions. They also 
learned about other causal connections by interacting with other persons and observing the social consequences of actions or the ways that others behave in relation to the emotional expression of personal feelings. But in addition to their knowledge of causality acquired in the context of their actions and interactions in the world, the children also learned about causality from the language they heard. Discourse is a major source for subjective meanings. Subjective causality, then, was a special instance in which something about the culture-how practices, judgments, affective states, and so forth, are valued as reasons for acting-is learned in the context of learning the language for its expression (Hood, Fiess, \& Aron, 1982; Schieffelin, 1990).

Not only did subjective causality from age 2 to 3 differ in this way from earlier sensorimotor causality, it also differed from Piaget's (1924/1972 description of psychological causality in preschool children. Piaget (1923/1955) reported that in response to such questions as "Why is there a great and little Saléve?" children gave animistic answers such as "Because there is one for little children and the other for big ones" and "Because of people who want to go into the little one or the great one" (pp. 228-9). He described such answers as "precausal" because children attributed psychological motivation to inanimate things out of "confusion between the psychical and the physical order of things" (p. 230). However, the children in the present study, though concerned very much with intentions and motivations, feelings and beliefs, gave no indication that they confused physical causality with the intentions of persons. The difference is they were talking about things they knew something about (Gelman, 1978). The children did not talk about, and adults did not ask them about, such physical phenomena as the sizes of lakes or the movement of clouds. When the children in the present study spoke for themselves, the content of their language and, presumably, their thinking as well centered on events for which their psychological explanations were appropriately causal.

Inherent in Piaget's genetic epistemology is the progressive approximation of the mind of the child to the mind of the scientist (Gruber \& Voneche, 1977). Accordingly, Piaget, as well as more recent psychologists investigating the development of causality (e.g., Bullock \& Gelman, 1979; Kun, 1978; Shultz, 1982), inquired into the child's understanding in terms of adult understanding of physical and logical phenomena. The theoretical models of causality tested in the developmental research have been based on correlations in the physical world or concepts of causal mechanism.

However, for the young children in this study, theories of causality that emphasize the actions and perceptions of persons in everyday causal events (e.g., Ducasse, 1924/1969; Hart \& Honoré, 1959; Lucas, 1962; Searle, 1983) were most relevant to the concept of causality attributable to them on the basis of the content of their language. The children displayed in their language an awareness of causality in the particular events and the human interactions that formed the contexts of their development. They discovered causal connections through their own and others' actions or heard them in everyday discourse. Causality, for them, was not the Humean "cement of the universe" that provides the structure of reality. Rather, causality was the means whereby they regulated their actions and their interactions in the world.

In sum, the construction of causality begins in infancy with the emergence of (1) an understanding of the relation between change and the actions of oneself and others (Piaget, 1937/1954) and (2) the detection of certain regularities in these events (e.g., Borton, 1979; Golinkoff et al., 1984). Before language, perceptible actions and their results are the child's only source of causal understanding. As language is acquired, the child can discover causal attributions through language. These are the bases-sensorimotor causality and causal attributions in discourse-upon which the 2-year-old child proceeds to construct an increasingly abstract understanding of causality. We propose that using causal language will be a large factor in deepening and extending the dimensions of their causal understanding and strategies for causal reasoning.

\section{Learning the Language of Causality}

These children's causal language provided a sample case of the transition in language development from simple to complex syntax. We know, from our earlier research into the acquisition of complex sentences, that the children we have studied acquired the syntax and connectives for connecting two propositions with additive, temporal, and causal meaning relations in the sequence: additive before temporal before causal (Bloom, Lahey, 
Hood, Lifter, \& Fiess, 1980). The fact that the children were already connecting propositions to express additive and then temporal meaning relations, before they connected propositions with causal meanings, is another instance of the observation that children first express new functions (in this case, causality) with old forms. Once a form is acquired with particular meaning, it can be used in acquiring other meanings (Bloom, 1970; Slobin, 1973; Werner \& Kaplan, 1963).

Although causal statements expressed subjective meanings first and most often, the children acquired syntactic connectives primarily in statements with objective meaning. This reversion to the sensorimotor- based, objective causal meanings in learning connectives is another instance of the observation that children frequently learn new forms to express established meanings. The implication here is that an advance in linguistic complexity has a constraining effect on the system (Bloom, Miller, \& Hood, 1975; Shatz, 1978). This effect is somehow mitigated when the content is familiar and well established, as means-end and consequence relations presumably were from infancy, as well as evident and verifiable in the context. This constraint on processing capacity, with the use of old forms for expressing new content and resorting to earlier learned content when learning new forms, is an instance of the effects on acquisition exerted from within the child.

We have seen, in these children's acquisition of the language of causality, how language, thought, and society influence one another in development. The closeness of objective meanings to sensorimotor causality provided evidence to support a hypothesis of cognitive priority. At the same time, subjective meanings provided an example of the influence from the language and society on thought. The children heard causal expressions in the speech that was directed to them, and they also participated in exchanges in which an adult's response to what they said was causally related. These were the contexts in which subjective meanings were acquired.

The results of this study are consistent with a model of development in which the child actively constructs both thought, in this instance the concept of causality, and the language. The concept of causality is constructed as the child acquires knowledge of persons, objects, and actions from evidential and linguistic events. Knowledge in memory, along with data from perception, provide the contents of psychological awareness, or intentional states in the philosophical sense, which the child endeavors to express through language and action. Language is constructed in the child's effort to express the underlying representations that are the contents of these states of mind (Bloom \& Beckwith, 1986). We have reported elsewhere that the children whom we have studied began using causal statements before they began to ask why questions. This means that development proceeded from talking about actions of self and others as expressions of what the child has in mind to the beginning of the ability to inquire into the contents of mind in others with why questions (Hood \& Bloom, 1979).

To conclude, the contents of the child's mental states give meaning to what the child does and says and direct the child to semantically relevant aspects of discourse for learning the language. This model of language development places the control of acquisition in the mind and action of the child (Bloom, Hood, \& Lightbown, 1974; Shatz, 1982), rather than in the events of the external context or the support the child receives in familiar interactions with adults. Events in the external context and the child's interactions are critically necessary, but it is the child's ability to understand and use these external events that is explanatory.

\section{REFERENCES}

Baron, N. (1977). Language acquisition and historical change. Amsterdam: North Holland.

Beer, C. (1973). A view of birds. In A. Pick (Ed.), Minnesota symposia on child psychology (vol. 7, pp. 47-86). Minneapolis: University of Minnesota Press.

Bloom, L. (1970). Language development: Form and function in emerging grammars. Cambridge, MA: MIT Press.

Bloom, L. (1974). The accountability of evidence in studies of child language. Comment on Everyday preschool interpersonal speech usage: Methodological, developmental, and sociolinguistic studies. In F. Schacter, K. Kirshner, B. Klips, M. Friedricks, \& K. Sanders (Eds.), Monographs of the Society for Research in Child Development, 39 (serial no. 156). 
Bloom, L. (1991). Language development from two to three. New York: Cambridge University Press.

Bloom, L., \& Beckwith, R. (1986). Intentionality and Language Development. Unpublished manuscript

Bloom, L., \& Lahey, M. (1978). Language development and language disorders. New York: Wiley.

Bloom, L., Capatides, J., \& Tackeff, J. (1981). Further remarks on interpretative analysis: In response to Christine Howe. Journal of Child Language, 8, 403-11.

Bloom, L., Hood, L., \& Lightbown, P. (1974). Imitation in language development: If, when and why. Cognitive Psychology, 6, 380-420.

Bloom, L., Lahey, M., Hood, L., Lifter, K., \& Fiess, K. (1980). Complex sentences: Acquisition of syntactic connectives and the semantic relations they encode. Journal of Child Language, 7, 235-61.

Bloom, L., Lightbown, P., \& Hood, L. (1975). Structure and variation in child language. Monographs of the Society for Research in Child Development, 40 (serial no. 160).

Bloom, L., Miller, P., \& Hood, L. (1975). Variation and reduction as aspects of competence in language development. In A. Pick (Ed.), Minnesota symposia on child psychology (vol. 9, pp. 3-55). Minneapolis: Borton, 1979;

Bowerman, M. (1974). Learning the structure of causative verbs: A study in the relationship of cognitive, semantic and syntactic development. In Papers and reports on child language development (No. 8, 142-78). Department of Linguistics, Stanford University.

Bullock, M., \& Gelman, R. (1979). Preschool children's assumptions about cause and effect: Temporal ordering. Child Development, 50, 89-96.

Bullock, M., \& Gelman, R., \& Baillargeon, R. (1982). The development of causal reasoning. In W. Friedman (Ed.), The developmental psychology of time (pp. 209-53). New York: Academic Press.

Ducasse, C. (1924/1969). Causation and the types of necessity. New York: Dover.

Gelman, R. (1978). Cognitive development. In M. Rosenzweig \& L. Porter (Eds.), Annual Review of Psychology, 29, 297-332.

Golinkoff, R. (1981). The case for semantic relations: Evidence from the verbal and nonverbal domains. Journal of Child Language, 8, 413-37.

Golinkoff, R., Carlson, V., Gibson, E., Harding, C., Sexton, M., Uzgiris, I., \& Watson, J. (1984). The development of causality in infants: A symposium. In L. Lipsitt \& C. Rovee-Collier (Eds.), Advances in infancy research (vol. 3, pp. 125-65). New York: Ablex.

Gruber, H., \& Voneche, J. (1977). The essential Piaget. New York: Basic Books.

Harris, M. (1964). The nature of cultural things. New York: Random House.

Hart, H., \& Honoré, A. (1959). Causation and the law. Oxford: Oxford University Press.

Hood, L., \& Bloom, L. (1979). What, when, and how about why: A longitudinal study of early expressions of causality. Monographs of the Society for Research in Child Development, 44 (serial no. 6).

Hood, L., Fiess, K., \& Aron, J. (1982). Growing up explained: Vygotskians look at the language of causality. In C. Brainerd \& M. Pressky (Eds.), Verbal processes in children (pp. 268-85). Berlin: Springer-Verlag.

Hume, D. (1739/1889). A treatise of human nature. In T. Green \& T. Grose (Eds.), The philosophical works (vol. 1). London: Longmans.

Kant, I. (1781/1965). Critique of pure reason. New York: Macmillan.

Knoke, D., \& Burke, P. (1980). Log-linear models. Beverly Hills, CA: Sage.

Kun, A. (1978). Evidence for preschoolers' understanding of causal direction in causal sequences. Child Development, 49, 218-22. 
Lucas, J. (1962). Causation. In R. Butler (Ed.), Analytical philosophy (pp. 32-65). New York: Barnes \& Noble.

Ochs, E., Schieffelin, B., \& Platt, M. (1979). Propositions across utterances and speakers. In E. Ochs \& B. Schieffelin (Eds.), Developmental pragmatics (pp. 251-68). New York: Academic Press.

Piaget, J. (1923/1955). The language and thought of the child. London: Kegan Paul.

Piaget, J. (1924/1972) Judgment and reasoning in the child. Totowa, NJ: Littlefield, Adams.

Piaget, J. (1930/1972). The child's conception of physical causality. Totowa, NJ: Littlefield, Adams.

Piaget, J. (1937/1954). The construction of reality in the child. New York: Basic Books.

Piaget, J. (1971/1974). Understanding causality. New York: Norton.

Schieffelin, B. (1990). The give and take of everyday life. Cambridge: Cambridge University Press.

Searle, J. (1983). Intentionality: An essay in the philosophy of mind. Cambridge: Cambridge University Press.

Sedlak, A., \& Kurtz, S. (1981). A review of children's use of causal inference principles. Child Development, 52, 759-84.

Shatz, M. (1978). The relationship between cognitive processes and the development of communication skills. In C. Keasey (Ed.), Nebraska symposium on motivation 1977: Social cognitive development (vol. 25, pp. 1-42). Lincoln: University of Nebraska Press.

Shatz, M. (1982). On mechanisms of language acquisition: Can features of the communicative environment account for development? In E. Wanner \& L. Gleitman (Eds.), Language acquisition: The state of the art (pp. 102-27). Cambridge: Cambridge University Press.

Shibatani, M. (Ed.) (1976). Syntax and semantics VI: The grammar of causative constructions. New York: Academic Press.

Shultz, T. (1982). Rules of causal attribution. Monographs of the Society for Research in Child Development, 47 (serial no. 194).

Slobin, D. (1973). Cognitive prerequisites for the development of grammar. In C. Ferguson \& D. Slobin (Eds.), Studies of child language development (pp. 175-208). New York: Holt, Rinehart \& Winston.

Trabasso, T., Stein, N., \& Johnson, L. (1981). Children's knowledge of events: A causal analysis of story structure. In G. Bower (Ed.), Learning and motivation (vol. 15, pp. 237-82). New York: Academic Press.

Vendler, Z. (1962). Effects, results and consequences. In R. Butler (Ed.), Analytical philosophy (pp. 1-15). New York: Barnes \& Noble.

Werner, H., \& Kaplan, B. (1963). Symbol formation. New York: Wiley. 